\title{
RUMO A UM ENSINO SUPERIOR 4.0: UMA EXPERIÊNCIA COM FÓRUM ON-LINE SÍNCRONO PARA ENSINO DE LÍNGUA INGLESA NA PERSPECTIVA DAS METODOLOGIAS ATIVAS
}

\author{
TOWARDS HIGHER EDUCATION 4.0: AN EXPERIENCE \\ WITH A SYNCHRONOUS ONLINE FORUM FOR \\ ENGLISH TEACHING FROM THE PERSPECTIVE OF ACTIVE \\ METHODOLOGIES
}

Mariana Backes NUNES 1

Patrícia da Silva Campelo Costa BARCELLOS ${ }^{2}$

\begin{abstract}
Resumo: Cada vez mais podemos perceber profundas mudanças na educação superior, principalmente com a onipresença dos aparatos digitais que permitem acesso a um número ilimitado de informações. O maior desafio dos professores atualmente é saber como integrar essas novas tecnologias em sala de aula, desenvolvendo habilidades inovadoras para viver em uma sociedade futura ainda em construção, promovendo uma Educação 4.0 (WALLNER; WAGNER, 2016). Assim, o objetivo deste trabalho é analisar a aplicação de metodologias ativas, como o ensino híbrido (MORÁN, 2015b), no ensino de língua inglesa, tendo as tecnologias digitais como mediadoras do processo de aprendizagem. Os participantes dessa pesquisa são graduandos em Letras com proficiência intermediária em inglês. Ao longo da pesquisa, foram aplicadas tarefas envolvendo ferramentas tecnológicas, tendo como temática principal a vida universitária. O foco do presente trabalho é a interação dos aprendizes em um fórum on-line realizado em uma aula presencial utilizando o Moodle. Foi observado que os alunos responderam positivamente à utilização do fórum on-line de forma síncrona, participando ativamente da discussão. Espera-se, com esse trabalho, incentivar a inserção das novas tecnologias no Ensino Superior, principalmente nos cursos de licenciatura, de maneira a expandir o leque de possibilidades que o ensinoaprendizagem de língua inglesa pode propiciar.
\end{abstract}

Palavras-chave: Ensino de Língua Inglesa. Novas Tecnologias. Ensino Híbrido. Educação 4.0. Fórum On-line Síncrono.
Abstract: Increasingly we can see profound changes in higher education, especially with the ubiquity of digital devices that allow access to an unlimited amount of information. The biggest challenge for teachers today is to integrate these new technologies into their lessons, developing innovative skills for our students to live in a future society still under construction, promoting Education 4.0 (WALLNER; WAGNER, 2016). Thus, the objective of this paper is to analyze the application of active methodologies, such as blended learning (MORÁN, 2015), in English language teaching, having digital technologies as mediators of the learning process. The participants in this research are undergraduates in Letters with intermediate English proficiency. Throughout the research, tasks involving technological tools were applied, having as main theme the university life. The focus of this study is the interaction of learners in a synchronous online forum using Moodle. It was observed that the students responded positively to the use of the forum, actively participating in the discussion. This study hopes to encourage the insertion of new technologies in higher education, especially in undergraduate courses, in order to expand the range of possibilities that English language teaching/learning can provide.

Keywords: English language teaching. New technologies. Blended learning. Education 4.0. Synchronous online forum.

1 Universidade do Vale do Rio dos Sinos (UNISINOS), São Leopoldo, Rio Grande do Sul, Brasil;
marianabackesnunes@gmail.com; https://orcid.org/0000-0003-3315-6370

2 Universidade Federal do Rio Grande do Sul (UFRGS), Porto Alegre, Rio Grande do Sul, Brasil; patricia. campelo@ufrgs.br; https://orcid.org/0000-0002-5142-4730 
- Rumo a um ensino superior 4.0: uma experiência com fórum on-line síncrono para ensino de língua inglesa na perspectiva das metodologias ativas

\section{Introdução}

A educação superior está passando por profundas mudanças com a inserção das novas tecnologias no ensino, e tais sinais devem ser levados em conta na organização do currículo acadêmico, bem como na formação de professores. Um dos maiores desafios dos professores atualmente é saber como integrar essas novas tecnologias em sala de aula, desenvolvendo habilidades inovadoras para viver em uma sociedade baseada em novas tecnologias ainda em construção.

Vemos em nosso cotidiano que novas habilidades e competências estão sendo constantemente cobradas, tais como, pensamento crítico e não linear, habilidades sociais e interculturais, assim como criatividade, autonomia, capacidade de resolução de problemas e colaboração são igualmente importantes (KERSCH; MARQUES, 2017). No entanto, a carência de discussões aprofundadas em cursos de licenciatura sobre as novas tecnologias e as habilidades que elas demandam está levando os professores a buscar conhecimento fora do ambiente universitário - seja em cursos livres, oficinas, blogs e websites, tutoriais do YouTube ou ainda com os próprios alunos (PAIVA, 2013). Por isso, é preciso urgentemente trazer tais discussões para dentro da universidade, aliando conhecimentos informais ao fazer acadêmico, de maneira a se preparar para um futuro nebuloso em que não sabemos como a tecnologia influenciará as nossas vidas. Precisamos, assim, de uma Educação 4.0.

Para tanto, o presente estudo tem como objetivo analisar a aplicação de metodologias ativas, como o ensino híbrido (MORÁN, 2015b), no ensino de língua inglesa, tendo as tecnologias digitais como mediadoras do processo de aprendizagem. Utiliza-se, então, da aplicação de forma síncrona de um fórum on-line em uma disciplina de estudo da língua inglesa para compreender esse fenômeno.

\section{Desafios para um Ensino Superior 4.0}

Atualmente, a educação superior vive um grande paradoxo. Segundo Valente (2014), ao mesmo tempo em que temos uma grande demanda de pessoas querendo entrar para a universidade, temos um percentual baixo de alunos que frequentam as aulas e, entre os estudantes que são assíduos, muitos estão fazendo outras coisas quando estão presentes em sala de aula. Vemos, então, que o modelo tradicional de ensino baseado na transmissão de conhecimento a partir da figura do professor não se sustenta mais, pois ele parte do pressuposto de que todos aprendem da mesma forma e no mesmo ritmo, o que não é o caso. Tal modelo foi implantado em uma era industrial em que o ensino tinha como 
objetivo formar trabalhadores eficientes, modelo denominado por Paulo Freire (1998) de educação bancária. No entanto, o novo modelo de educação, influenciado pelo advento das novas tecnologias de informação, exige um papel ativo dos aprendizes, em que esses estejam aptos a tecer conexões entre os conhecimentos adquiridos via educação formal e as situações concretas vivenciadas no dia a dia.

Para Wallnear e Wagner (2016), a onipresença dos aparatos digitais e das redes sociais mudou a forma com que os alunos possuem acesso a informações. O professor não é mais a única fonte do saber, pois o aluno encontra informações em todos os lugares, bastando estar conectado a web. Além de ter acesso rapidamente aos conteúdos, o aluno também tem contato com diferentes tipos de conhecimento, seja através de textos acadêmicos e apresentações, ou até mesmo através de tutoriais e vídeos da internet.

O rápido progresso do conhecimento em diferentes áreas graças às tecnologias igualmente nos leva a refletir sobre a organização curricular dos cursos oferecidos nas universidades. Tradicionalmente, a divisão do ensino por cursos, disciplinas e conteúdos refletiu a tendência de padronizarmos o mundo acadêmico ao simplificar a complexidade do mundo exterior a colocando em múltiplas caixas, o que distanciou a universidade de situações reais de aplicação do aprendizado. Oliveira, Tinoco e Santos (2014) afirmam que o mundo acadêmico precisa deixar de lado a fragmentação dos saberes, isto é, a sua compartimentação em conteúdos e disciplinas rígidas que levam a um trabalho sem relação com o mundo além dos seus muros. Os autores, então, nos provocam com o seguinte questionamento: "se na vida a complexidade dos fenômenos não pressupõe a fragmentação, mas a complementação de ações, por que na escola só podemos operar em termos de disciplinas e conteúdos fragmentados?" (OLIVEIRA; TINOCO; SANTOS, 2014, p. 22).

Por isso, Wallnear e Wagner (2016) defendem que a educação superior deve se voltar a problemas transdisciplinares que aproximam áreas de pesquisa relacionadas, de maneira a responder à complexidade do dia a dia com complexidade, ao partir do princípio de que nossos alunos precisam ter como referência uma visão geral do campo de estudo do qual fazem parte. Um desses movimentos é a criação de programas modulares de estudo, que não apenas facilitam um trabalho transdisciplinar, como também incentivam maior autonomia por parte do aluno na organização de seus estudos.

Da mesma forma, a variabilidade de configurações e formatos de aulas mediadas por tecnologias possibilita um aprendizado colaborativo e engajado, que respeita o ritmo do aluno (WALLNEAR; WAGNER, 2016). Tais configurações nos levam a repensar o próprio espaço de sala de aula. Os ambientes de aprendizado desempenham papel importante 
- Rumo a um ensino superior 4.0: uma experiência com fórum on-line síncrono para ensino de língua inglesa na perspectiva das metodologias ativas

nesse processo e, por isso, ao pensar um novo modelo de educação, o espaço deve ter menos formato de palestra, como tradicionalmente conhecemos, e mais um formato acolhedor a diferentes experiências, sejam elas individuais ou em grupos, presenciais ou virtuais (PUNCREOBUTR, 2016).

Assim, ao ver o aprendizado como uma atividade social, devemos considerar abrir as portas das salas de aulas para interações e discussões além do campus, formando redes pessoais de aprendizagem. As redes pessoais de aprendizagem, segundo Dudeney, Hockly e Pegrum (2016), são redes digitais confiáveis que integram pessoas - sejam especialistas ou interessados no assunto em questão - que servirão como fonte de apoio através do compartilhamento de informação. Nessas redes ocorre a troca de recursos vivos e materiais, servindo como filtros de informação e espaços de aprendizagem, colaboração e disseminação. Para os autores,

[...] redes pessoais de aprendizagem também anunciam um distanciamento dos modelos de educação industriais e padronizados, promovendo a customização individual da aprendizagem, quebrando barreiras entre a sala de aula e o mundo e instigando o desenvolvimento profissional contínuo. (DUDENEY; HOCKLY; PEGRUM, 2016, p. 46).

No entanto, as características até então assinaladas só serão possíveis em um contexto de aprendizagem ativa, focado nos conhecimentos prévios do aluno, na inovação e na resolução de problemas, isto é, em um ambiente voltado a uma Educação 4.0 (WALLNER; WAGNER, 2016; PUNCREOBUTR, 2016). Criado a partir das necessidades da indústria 4.0, indústria que combina sistemas físicos e cibernéticos, o conceito de Educação 4.0 prevê um ensino-aprendizagem com foco no learning by doing, ou seja, no aprendizado a partir da experimentação e da vivência em um ambiente de Web 4. $0^{3}$, uma web que ainda não possui definição exata, mas que é comumente denominada de web simbiótica, que prevê a interação entre humanos e máquinas em simbiose (AGHAEl; NEMATBAKHSH; FARSANI, 2012; SALMON, 2019).

\footnotetext{
3 Durante muitos anos a web foi utilizada somente para uso, recepção e consumo de conteúdos criados por empresas. A Web 1.0 tinha como enfoque a transmissão e, por isso, o usuário tinha papel passivo sendo mero espectador do conhecimento ali transmitido (MORAIS et al., 2012; SALMON, 2019). Já a Web 2.0 passou a representar a aproximação da web ao usuário, pois a plataforma se tornou potencializadora da interação, colaboração e distribuição. A Web 2.0 é chamada por Salmon (2019) de web social. Por sua vez, a Web 3.0 é também chamada de web semântica, pois traz programas que interpretam "um conjunto de tecnologias com formas mais eficientes para ajudar os computadores a organizar e analisar a informação disponível na rede" (MORAIS et al., 2012, p. 66). No entanto, devemos nos preparar para uma Web 4.0, a web simbiótica, da qual trata o presente artigo.
} 
Logo, o grande impacto da Educação 4.0 será a enorme conectividade e a interação entre humanos e máquinas, o que nos faz incapazes de prever ou entender os seus significados a longo prazo (SALMON, 2019). Como será a sociedade após grandes avanços tecnológicos tais como os vistos na robótica, internet das coisas, nanotecnologia e computação quântica? E quais mudanças essas invenções trarão para a educação? Ainda não sabemos, mas devemos refletir e nos voltar a esses casos. Para tanto, as universidades devem estar em constante adaptação às novas demandas de ensino, de maneira a instigar as novas gerações, as gerações de DNA digital, a estarem presentes integralmente em seu processo de aprendizagem, experienciando e reconstruindo o próprio ambiente acadêmico.

É preciso, então, desenvolver competências que auxiliem os educandos a viver em uma sociedade globalizada e virtualizada ainda em construção. Ou seja, precisamos fomentar uma educação mais cidadã que esteja voltada para o futuro que temos à frente, um futuro nebuloso que muda a cada instante e que exige flexibilidade, criatividade e respeito à cultura do outro (KERSCH; MARQUES, 2017). Habilidades tais como letramento digital, colaboração, comunicação, criatividade, capacidade de resolução de problemas, de pensamento crítico e de aprendizado autodidata, além das competências socioemocionais, serão cada vez mais importantes e devem ser instigadas no ambiente educacional como um todo.

Tais habilidades, contudo, não serão efetivamente desenvolvidas apenas com a inserção das novas tecnologias em sala de aula. Como bem marcado por Gallagher (2019), "o aprendizado precisa ser reimaginado para os futuros emergentes de trabalho" ${ }^{4}$, ou seja, as novas tecnologias devem ser utilizadas com propósitos pedagógicos inovadores bem claros e em que elas se fazem necessárias, combinando, assim, o melhor da tecnologia com o melhor do ensino humano (SALMON, 2019). Desse modo, faz-se cada vez mais indispensável um ensino híbrido que combina o ensino virtual com o ensino presencial.

\section{Metodologias ativas, ensino híbrido e o ensino-aprendizagem de língua estrangeira}

Como vimos anteriormente, o conceito de Educação 4.0 nos alerta que precisamos reinventar nossas práticas educacionais para integrar a nova geração de aprendizes e desenvolver habilidades que os ajudem a circular em futuras práticas sociais mediadas

4 No original: "Learning has to be re-imagined for the emerging futures of work". Disponível em: https://www. swinburne.edu.au/new-workforce/. Acesso em: 11 out. 2019. 
- Rumo a um ensino superior 4.0: uma experiência com fórum on-line síncrono para ensino de língua inglesa na perspectiva das metodologias ativas

por tecnologias. As metodologias ativas, por exemplo, nos fornecem subsídios para auxiliar os alunos a terem autonomia e a serem protagonistas do seu próprio aprendizado. Pimentel e Teixeira (2018, p. 145) explicam que as metodologias ativas se tratam de qualquer abordagem que instiga o aluno a "participar ativamente das aulas, construindo conhecimento a partir da reflexão crítica dos conteúdos propostos pelo professor". Por sua vez, Sperhacke et al. (2016) destacam que as metodologias ativas permitem que o aluno seja responsável por sua educação, o que o motiva a estar mais comprometido com a construção de saberes.

Pela perspectiva das metodologias ativas, o professorassumiria o papel de facilitador da aprendizagem, propondo desafios que incentivem os alunos a buscar informações, conteúdos e teorias que serão a base dos conhecimentos construídos e aplicados em simulações, projetos e jogos feitos em sala de aula. E esse processo de construção de conhecimento não se encerra em sala de aula, pois extrapola o ambiente e se perpetua para toda a vida, visto que o aprendiz não apenas aprende, como também ensina, compartilha, colabora, coopera, ampliando o sentido daquilo que está aprendendo (SPERHACKE et al., 2016; PIMENTEL; TEIXEIRA, 2018). Vemos comumente na literatura como exemplos de metodologias ativas a aprendizagem baseada em problemas, a aprendizagem baseada em projetos, a sala de aula invertida, a instrução entre pares, o ensino híbrido, entre outras abordagens. No presente artigo, por sua vez, nos concentramos no conceito de ensino híbrido.

O ensino híbrido é uma abordagem educacional que integra a interação face a face com a instrução on-line em uma interligação simbiótica profunda e constante (DZIUBAN et al., 2018; MÓRAN, 2015a). Também chamado de blended learning, esse modelo vê a aprendizagem como um processo contínuo, que ocorre de diferentes formas e em diferentes espaços, ampliando o escopo das formas de aprendizagem (BACICH; NETO; TREVIANI, 2015). Morán (2015a), porém, ressalta que o ensino sempre foi híbrido, isto é, sempre existiu uma mescla de espaços, metodologias ou públicos na área da educação; no entanto, essa mistura está cada vez mais perceptível, pois o mundo virtual é um ecossistema mais aberto e criativo que aumentou as possibilidades de ensino radicalmente.

De acordo com Morán (2015a, p. 16), o ensino híbrido vê a sala de aula de forma ampliada, não considerando apenas o seu espaço físico tradicional como propulsor da aprendizagem, mas os múltiplos espaços do cotidiano, incluindo os digitais, ou seja, o ensino híbrido tem como objetivo "abrir a escola para o mundo e trazer o mundo para dentro da escola". Essa metodologia busca, então, utilizar o máximo de oportunidades de aprendizagem de maneira a alcançar um ambiente de aprendizagem otimizado. Contudo, 
o ambiente físico das salas de aula não poderá continuar o mesmo que conhecemos atualmente, deve ser redesenhado nessa nova concepção. Como já comentado anteriormente, as salas de aula precisam ser mais multifuncionais, combinando facilmente atividades em grupo, de plenário e individuais, não deixando de integrar o estudo e o lazer. Também devem estar sempre conectadas à internet, não apenas em seus computadores, mas também a uma rede sem fio para o uso das tecnologias móveis, hoje tão difundidas.

É igualmente importante salientar que, em uma educação baseada no ensino híbrido, o professor tem o papel de curador e orientador, não mais sendo o transmissor do conhecimento. Curador porque escolhe o que é relevante a ser estudado naquele momento no meio de tanta informação presente na web; orientador porque cuida, ampara, acolhe e estimula o aluno a buscar sempre mais conhecimento (MORÁN, 2015a). Outra vantagem do emprego do ensino híbrido é que esta abordagem respeita o ritmo de aprendizagem de cada aluno ao compreender que cada indivíduo aprende de forma diferente e no seu tempo, dando espaço para que o professor-orientador possa equilibrar o ensino entre aprendizagens pessoais e grupais. Tem-se, assim, como premissa do ensino híbrido que

Aprendemos por meio de processos organizados, junto com processos abertos, informais. Aprendemos quando estamos com um professor e aprendemos sozinhos, com colegas, com desconhecidos. Aprendemos de modo intencional e de modo espontâneo, quando estudamos e também quando nos divertimos. Aprendemos com o sucesso e com o fracasso. Hoje, temos inúmeras formas de aprender. (MORÁN, 2015b, p. 28).

No ensino-aprendizagem de uma língua estrangeira, mais especificamente, o ensino híbrido oferece muitos benefícios, principalmente por combinar aulas presenciais e virtuais e estimular abordagens pedagógicas centradas no aluno. Beviláqua, Kieling e Leffa (2019), por exemplo, relatam a experiência de suas professoras em formação ministrando aulas em um curso de extensão de língua inglesa de uma universidade em contexto de ensino híbrido. Segundo os autores, ambas as professoras salientaram que a utilização de ferramentas digitais para além da sala de aula, tais como Facebook e WhatsApp, assim como a abordagem por Rotação de Estações ${ }^{5}$, motivou os alunos a participar mais ativamente das aulas, assim como estes obtiveram um resultado significativo ao final do curso, como o aumento de vocabulário na língua em questão,

5 Modelo de ensino híbrido em que se organizam os aprendizes em grupos que, por sua vez, revezarão a realização de pequenas tarefas, trocando de tarefa conforme o tempo estipulado previamente entre eles e o professor, de maneira a atingir um objetivo em comum (BEVILÁQUA et al., 2019). 
- Rumo a um ensino superior 4.0: uma experiência com fórum on-line síncrono para ensino de língua inglesa na perspectiva das metodologias ativas

o que também foi reconhecido pelos próprios estudantes. Os pesquisadores, então, salientam a importância de termos exemplos de aplicação do ensino híbrido e demais metodologias ativas na própria formação inicial docente, possivelmente impulsionando, assim, mudanças futuras na educação básica.

Logo, vemos que as novas tecnologias auxiliam o aprendiz de língua estrangeira a enriquecer as suas experiências com a língua em questão, ampliando o seu insumo através do leque de possibilidades de material autêntico que podemos encontrar na web. Elas também aproximam o aluno de uma audiência real de comunicação, pois seus textos podem ser publicados na web e, assim, lidos por pessoas de diferentes partes do globo, tornando-se produções significativas ao ter leitores reais para os seus textos, não somente o professor avaliador (BUTLER-PASCOE; WIBURG, 2003). O ensino híbrido, por sua vez, forneceria novas possibilidades de contato e de utilização da língua estrangeira para além da sala da aula, garantindo que o aluno a empregue em diferentes situações em seu cotidiano, não apenas nas poucas horas semanais que ele está presente na universidade.

\section{Metodologia}

A metodologia empregada neste trabalho é de abordagem qualitativa e de cunho interpretativista descritivo, pois busca explorar os significados que um grupo de participantes possui sobre um determinado fenômeno social, incluindo uma reflexão crítica sobre o próprio fazer investigativo (CRESWELL, 2010; DE GRANDE, 2011). Assim, os participantes dessa pesquisa são onze graduandos em Letras de uma universidade pública, ainda no primeiro semestre do curso e com proficiência intermediária em língua inglesa. A escolha de tais informantes deve-se à importância de incentivar estudantes/ futuros professores de língua a utilizarem materiais tecnológicos de maneira reflexiva em suas práticas acadêmicas e pedagógicas.

Ao longo da pesquisa, as aulas de língua inglesa foram realizadas de modo presencial, em um laboratório de informática, tendo disponíveis computadores conectados à internet e um projetor ligado ao computador do professor. Os alunos também poderiam utilizar a rede wi-fi em seus dispositivos móveis. As tarefas realizadas em aula também poderiam ser acessadas pelos aprendizes após aquele momento, pois eram publicadas em ambientes virtuais de aprendizagem, como o Moodle e o Pbworks, sendo o foco desta pesquisa um fórum criado no Moodle. É importante explicitar tais detalhes justamente por ser uma forma de ressignificar o ambiente de sala de aula, ao pensar que ele é constituído por elementos além de mesas, cadeiras e um quadro negro, como vemos em contextos tradicionais de ensino. 
Cabe aqui também salientar que as aulas voltadas ao estudo da língua inglesa do curso de graduação desta universidade são pautadas pela pedagogia de projetos, tendo, a cada semestre, uma temática a ser explorada. A aprendizagem baseada em projetos igualmente pode ser considerada uma metodologia ativa por pressupor que o aprendizado se dá por meio do diálogo e da indagação, colocando docentes e estudantes no papel de protagonistas do aprendizado, como autores de conhecimento e de saber pedagógico (WELP; VIAL, 2016). Na pedagogia de projeto, os projetos são gerados em torno de uma pergunta instigadora ou de um tema a ser estudado em profundidade. Logo, durante o estudo aqui analisado foram aplicadas tarefas envolvendo ferramentas tecnológicas, tendo como temática principal a vida universitária, já que se tratava de uma disciplina de início de curso. O objetivo da disciplina era não apenas promover o ensino e a reflexão da língua estrangeira em questão, mas também ser um ambiente acolhedor para esses estudantes novatos, em que esses poderiam debater questões referentes ao próprio mundo universitário.

Como mencionado anteriormente, no presente trabalho, será analisada uma tarefa deste projeto, pois se tem como foco a interação dos aprendizes em um fórum on-line realizado em uma aula presencial utilizando o Moodle. Dessa forma, no fórum aqui examinado, os alunos deveriam postar um comentário sobre como eles se veem sendo um estudante universitário novato, além de responder a um comentário feito pelos colegas, interagindo sempre na língua estrangeira em questão, como mostrado na imagem abaixo (Figura 1).

Figura 1. Instruções para o fórum Freshman Student

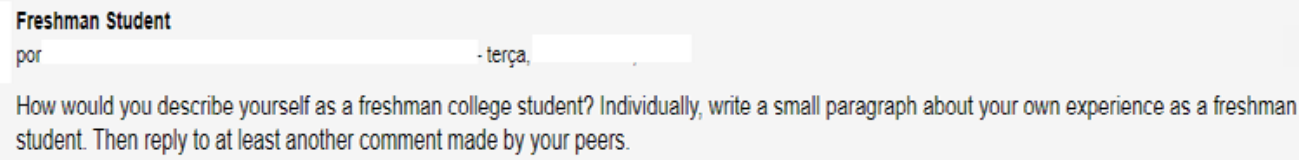

Fonte: Elaboração própria

Essa tarefa tinha, então, como objetivo instigar os alunos a compartilharem suas próprias experiências, traçando um perfil do estudante novato, assim como aproximar os aprendizes ao reconhecerem características semelhantes às suas no outro, tudo isso empregando a língua inglesa em suas interações. Logo, a fim de investigar a interação dos alunos nesse fórum, fazem parte dos dados desta pesquisa: as postagens dos alunos no fórum denominado Freshman Student, as observações realizadas pela pesquisadora 
- Rumo a um ensino superior 4.0: uma experiência com fórum on-line síncrono para ensino de língua inglesa na perspectiva das metodologias ativas

durante a realização da tarefa e as respostas a um questionário respondido ao final pelos participantes, através da ferramenta Google Forms ${ }^{6}$.

\section{Análise e discussão}

O interessante do fórum on-line ter sido realizado neste estudo em uma aula síncrona é que ele combinou aspectos positivos de dois gêneros digitais tradicionais, o fórum e o chat. Como bem explicam Cabeda (2005) e Morais e Cabrita (2008), o fórum virtual é comumente utilizado em atividades assíncronas, pois possibilita que o aprendiz possa participar da atividade ao seu tempo, tendo liberdade para definir a sua participação e a profundidade de suas reflexões, assim como dá ao estudante a oportunidade de editar o seu texto mesmo após a publicação. O fórum também traz vantagens ao professor, uma vez que organiza as mensagens em tópicos e eixos de discussão, salvando informações essenciais, tais como, data de postagem, autor e assunto. Contudo, uma tarefa realizada através de um fórum on-line deve ser bem estruturada pelo professor orientador, visto que em muitos casos os estudantes acessam o fórum, publicam a sua postagem e esquecem de voltar ao ambiente para acompanhar a discussão.

Por seu turno, o chat, gênero característico das atividades síncronas, proporciona uma proximidade virtual em tempo real aos seus participantes, ao mesmo tempo em que se trata de um gênero mais informal. No entanto, para participar de um chat é necessário um esforço maior do usuário para poder acompanhar o ritmo da discussão: o participante deve ler as postagens e redigir as suas respostas em pouco tempo, não tendo a oportunidade de se aprofundar na escrita, nem mesmo realizar correções e edições em seu texto. Outro fator a se considerar é que, para que um chat funcione adequadamente em contexto educacional, isto é, sem acontecer imprevistos e confusões, é preciso um planejamento detalhado por parte do professor em relação a regras, objetivos, número de participantes e duração do chat (CABEDA, 2005; MORAIS; CABRITA, 2008).

6 Disponível em: https://www.google.com/forms/about/ Acesso em: 11 out. 2019. 
Gráfico 1. Comparações entre os gêneros digitais Chat e Fórum
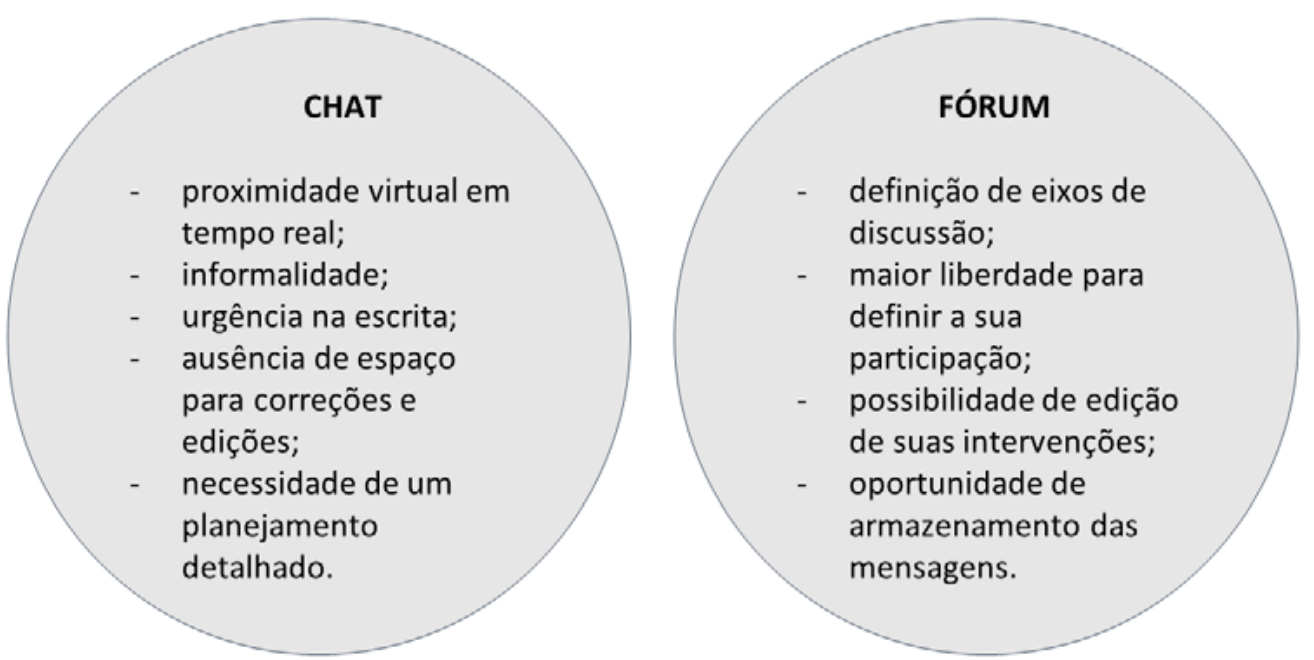

Fonte: Elaboração própria com base em Cabeda (2005) e Morais e Cabrita (2008)

Por conseguinte, o fórum on-line síncrono empregado na tarefa aqui analisada combinou a proximidade e ainformalidade dochatcom a possibilidade de aprofundamento e reflexão do fórum, assim como permitiu o armazenamento das interações ali realizadas para posterior análise. Também foi uma forma de atrair o aluno a participar da discussão, interagindo com o grupo sem a inibição que a conversa face a face poderia causar, como veremos na análise a seguir.

No fórum Freshman Student, os alunos foram instigados a compartilhar as suas experiências universitárias como novatos, utilizando a língua inglesa nesse processo, de maneira a definir o perfil de um freshman student. Para que os alunos pudessem interagir no fórum de forma mais dinâmica, ainda mais se tratando de uma tarefa síncrona, foi estipulado pela professora que os alunos deveriam comentar pelo menos uma postagem dos colegas. Os alunos, apesar de um pouco intimidados com o fato de terem que dividir as suas vivências com os demais, participaram ativamente da tarefa com entusiasmo, voltando ao fórum várias vezes durante a aula para comentar mais de uma postagem e aguardar uma resposta ao seu próprio compartilhamento.

Em suas produções, os alunos utilizaram, em sua maioria, a variante informal da língua inglesa, por exemplo, a utilização de contrações ("it'd", "I don't", "it's") e de expressões informais ("pretty much", "meet a bunch of new people") (Figura 2 e Figura 3). Isso ocorre justamente por se tratar de um texto que abordava as suas próprias experiências e opiniões. Os aprendizes também exploraram as ferramentas dispostas pela plataforma Moodle, empregando diferentes linguagens, além da linguagem escrita, tais como, imagens e vídeos, como exemplificado na Figura 3. 
- Rumo a um ensino superior 4.0: uma experiência com fórum on-line síncrono para ensino de língua inglesa na perspectiva das metodologias ativas

Figura 2. Exemplos de postagens e comentários publicados no fórum on-line síncrono

\section{Freschman Student}

Re: Freshman Student

por

- terça, $\quad 11: 14$

At first, I thought college would be life changing, that it'd make me more responsible, more of an adult I was excited about it, but when it started I realized it wouldn't change me if I didn't want to. It's nice that it's a new life phase, a new challenge, but I don't feel like it's that much different from school - or at least not as different as I thought it'd make me feel about it.

Re: Freshman Student

por $\quad$ - terça 1120

College is pretty much just high school with more self-accountability and alcohol. honestly. It's more that, as time passes, you end up becoming more independent, either because of responsabilities or new experiences, like living by yourself. It happens gradually.

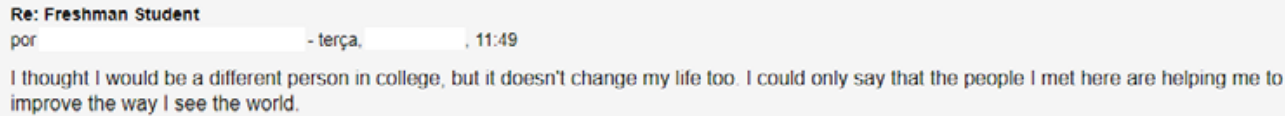

I thought I would be a different person in college, but it doesn't change my life too. I could only say that the people I met here are helping me to improve the way I see the world.

Link direto | Mostrar principal

Fonte: Dados das autoras

Figura 3. Exemplo de postagem publicada no fórum on-line síncrono Freshman Student

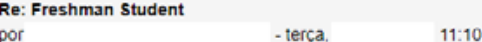

As a freshman college student I was very excited at the beggining, a little scared, that's true, but full of expectations and plans. My biggest wish were eat at RU, meet a bunch of new people and learn a lot about linguistic, english, latim and another subjects that I never had the chance of getting deep into. Sometimes I felt a little insecure, but that's normal and only gets worse.

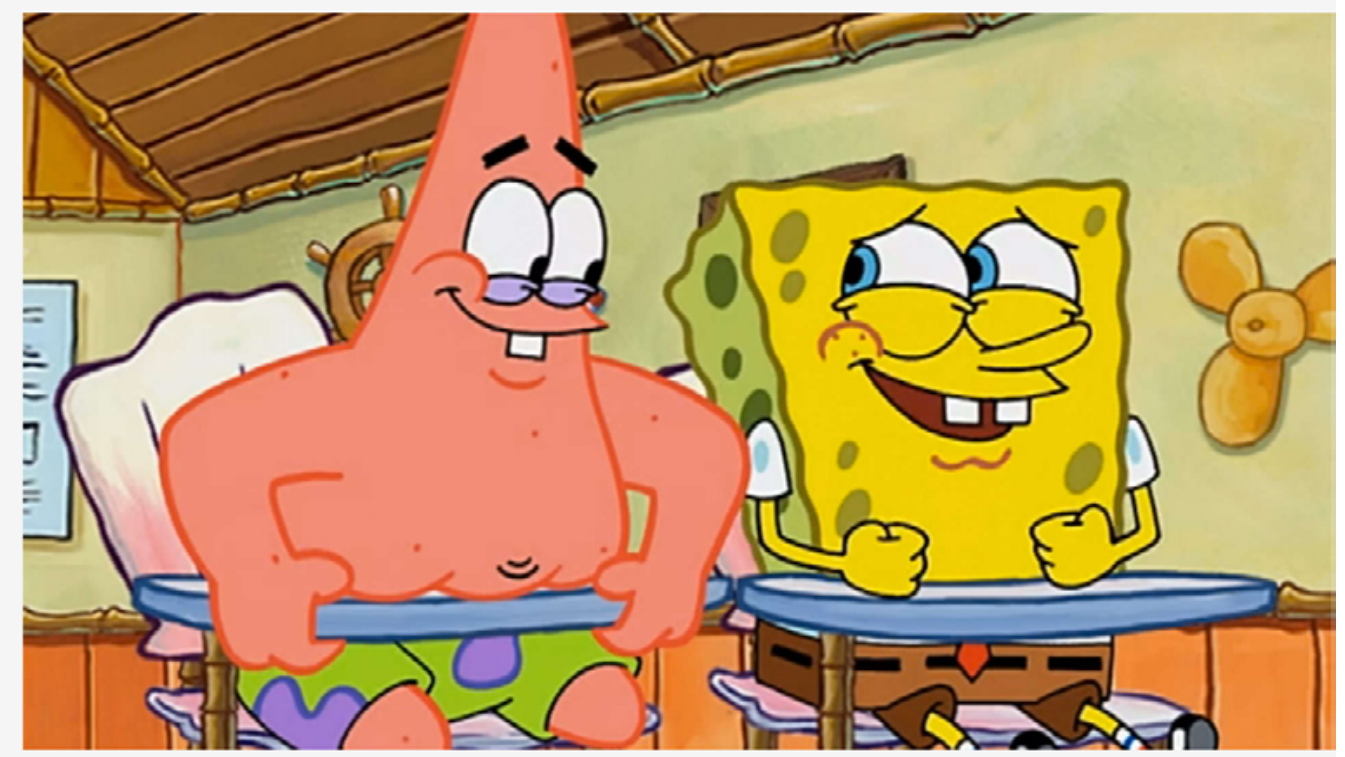

Fonte: Dados das autoras 
Como se tratava de uma discussão entre estudantes/novatos sobre as suas primeiras experiências na universidade, é notável em suas publicações que os alunos experienciam os dilemas e desafios do ensino superior nesta era tecnológica. Os próprios refletem sobre as mudanças que ocorreram em seu dia a dia e em sua rotina de estudo ao se deparar com tarefas próprias do ensino híbrido em disciplinas da universidade, como a disciplina em que esta pesquisa foi aplicada. Na Figura 4, vemos em uma postagem a aluna relatando que, ao entrar na universidade, se deparou com novas ferramentas tecnológicas voltadas à aprendizagem, as quais antes não faziam parte do seu aprendizado, como o próprio Moodle, o Google Drive, o portal do aluno no site da universidade, entre outras:

Figura 4. Exemplo de postagem publicada no fórum on-line síncrono Freshman Student
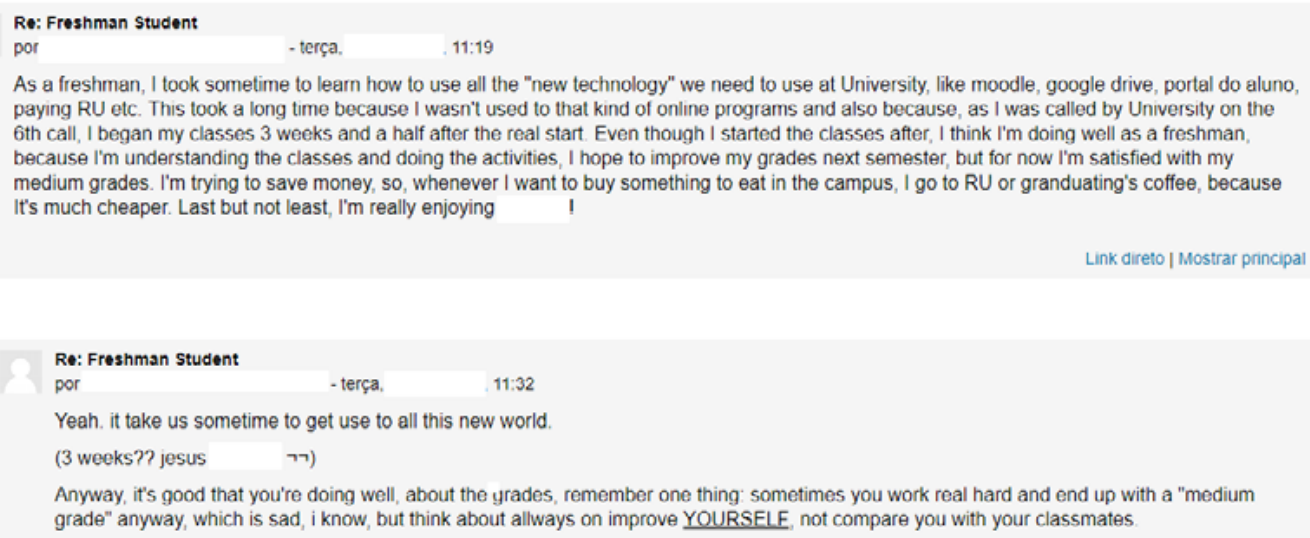

Fonte: Dados das autoras

A recepção dos alunos à tarefa do fórum on-line síncrono foi positiva. No questionário aplicado ao final da pesquisa, os alunos relataram que essa troca de vivências ocorridas na universidade ajudou a turma composta prioritariamente de novatos a se conhecer e se integrar, como fica claro na seguinte fala de uma aluna: "As tarefas ajudaram na integração da turma nas atividades que envolviam interação com todos os colegas (como os fóruns em que comentamos os trabalhos um dos outros)". O mesmo é exposto por outro aluno ao afirmar que "os pontos positivos (da tarefa) foram: poder relacionar as ideias, convergentes ou divergentes, e descobrir que muitos universitários têm os mesmos problemas e alegrias dentro do espaço acadêmico".

Com estes relatos dos alunos podemos ver que o fórum on-line síncrono não apenas foi um momento de utilizar a língua inglesa na escrita de uma postagem para um fórum, como também foi um momento de interação produtivo, em que os alunos se reconheceram no outro ao compartilharem vivências universitárias. Portanto, o fórum on-line síncrono se tornou um momento descontraído para os estudantes, em que estes 
- Rumo a um ensino superior 4.0: uma experiência com fórum on-line síncrono para ensino de língua inglesa na perspectiva das metodologias ativas

utilizaram para interagir com os colegas de sala de aula de uma maneira que, falando abertamente em público, realmente face a face, talvez não conseguissem realizar, seja por timidez ou por medo de errar em frente à turma.

Nota-se, no presente estudo, que a sala de aula de uma disciplina de ensino superior foi ressignificada de modo a abranger os diferentes espaços e artefatos de aprendizagem presentes em nossa sociedade, ampliando as possibilidades dos aprendizes de produzir conhecimento e construindo, assim, um contexto de ensino híbrido. O uso de plataformas como o Moodle deve ser aqui salientado, principalmente porque, apesar de já conhecido pelos docentes universitários, pouco são exploradas as suas inúmeras possibilidades (BLIN; MUNRO, 2008), como é o caso do próprio fórum, sendo que, como bem mostrado na tarefa aqui analisada, ainda pode ser utilizado em diferentes abordagens de ensino.

A temática do projeto e a tarefa proposta aos alunos durante esta pesquisa buscaram suprir as necessidades dos aprendizes por interação e troca de experiências em seu primeiro semestre do curso, utilizando-se da mediação da tecnologia. Trata-se de uma proposta de ensino mais dialogada, tendo como protagonista do aprendizado o estudante, em que este pode, através do emprego da língua inglesa, apresentar a sua opinião e ser ouvido pelos seus pares. Compreendemos que uma Educação 4.0 não apenas é formada por tecnologias presentes no contexto educativo, mas também por redes de aprendizagem colaborativas que se tornam possíveis graças a elas, tornando o aprendizado de uma língua ainda mais significativo.

\section{Considerações finais}

Os altos avanços da tecnologia em diferentes áreas da nossa sociedade nos levam a pensar em uma Educação 4.0, isto é, uma educação centrada na alta conectividade e na simbiose de metodologias e ferramentas, de maneira a planejar estratégias para um futuro incerto que aguarda nossos alunos em seu venturo mercado de trabalho. Para acompanhar essas mudanças, o ensino superior que conhecemos precisará passar por profundas reformulações, as quais aos poucos estamos vendo nos campi das nossas universidades, mas que ainda têm uma longa jornada a seguir.

Na aula de língua estrangeira, sabemos que devemos progressivamente maximizar a interação em sala de aula, e fora dela, utilizando diferentes metodologias - e aqui defendemos também o uso de diferentes tecnologias - de maneira a incentivar o aluno a ser o protagonista do seu próprio aprendizado. Estudos nos mostram que o ensino híbrido colabora na satisfação e no sucesso dos alunos, assim como desenvolve um senso de comunidade em comparação com cursos presenciais tradicionais (BERNARD et al., 2014; DZIUBAN et al., 2018), o que também foi encontrado na presente investigação. 
Percebemos que os aprendizes participantes desta pesquisa responderam positivamente à abordagem do ensino híbrido em uma disciplina de língua inglesa do curso de Letras. Da mesma forma, a utilização do fórum on-line de forma síncrona foi propícia para instigar a interação dos alunos e a sua participação ativa durante a discussão, pois os motivou a voltar frequentemente a sua atenção ao Moodle durante a aula para verificar as ideias trazidas pelos colegas ao debate.

Espera-se, com esse trabalho, incentivar a inserção das novas tecnologias no Ensino Superior, principalmente nos cursos de licenciatura. A formação de novos professores precisa estar cada vez mais integrada às metodologias ativas e voltada a um futuro que ainda temos a construir. Falar apenas sobre a inserção das novas tecnologias no ensino não basta; é preciso agirmos de maneira a acompanhar as constantes mudanças do mundo digital, rumo a um Ensino Superior 4.0.

\section{Agradecimentos}

O presente trabalho foi realizado com apoio da Coordenação de Aperfeiçoamento de Pessoal de Nível Superior - Brasil (CAPES) - Código de Financiamento 001.

\section{Referências}

AGHAEI, S.; NEMATBAKHSH, M. A.; FARSANI, H. K. Evolution of the world wide web: from web 1.0 to web 4.0. In: International Journal of Web \& Semantic Technology (IJWesT), v. 3, n. 1, p. 1-10, 2012. Disponível em: http://airccse.org/journal/ijwest/ papers/3112ijwest01.pdf. Acesso em: 3 out. 2018.

BACICH, L.; NETO, A. T.; TREVISANI, F. de M. Ensino híbrido: personalização e tecnologia na educação. Porto Alegre: Penso, 2015.

BERNARD, R. M.; BOROKHOVSKI, E.; SCHMID, R. F.; TAMIM, R. M.; ABRAMI, P. C. A meta-analysis of blended learning and technology use in higher education: From the general to the applied. Journal of Computing in Higher Education, v. 26, n. 1, p. 87-122, 2014.

BEVILÁQUA, A. F.; KIELING, H. dos S.; LEFFA, V. J. A implementação do ensino híbrido no ensino de inglês durante a formação docente. Caderno Seminal Digital, n. 33, v. 33, jul./ dez. 2019. 
- Rumo a um ensino superior 4.0: uma experiência com fórum on-line síncrono para ensino de língua inglesa na perspectiva das metodologias ativas

BLIN, F.; MUNRO, M. Why hasn't technology disrupted academics' teaching practices? Understanding resistance to change through the lens of activity theory. Computers \& Education, v. 50, p. 475-490, 2008.

BUTLER-PASCOE, M. E.; WIBURG, K. M. Technology and teaching English language learners. Boston: Pearson Education, 2003.

CABEDA, M. O chat-fórum: uma ideia de uso híbrido síncrono e assíncrono, através de uma única ferramenta normalmente assíncrona, o fórum virtual. In: $12^{\circ}$ Congresso Internacional de Educação a Distância, 2005.

CRESWELL, J. W. Projeto de pesquisa: métodos qualitativo, quantitativo e misto. 3. ed. Porto Alegre: Artmed, 2010.

DE GRANDE, P. B. O pesquisador interpretativo e a postura ética em pesquisas em Linguística Aplicada. Eletras, v. 23, n. 23, p. 11-27, dez. 2011.

DUDENEY, G.; HOCKLY, N.; PEGRUM, M. Letramentos digitais. Tradução Marcos Marcionilo. São Paulo: Parábola Editorial, 2016.

DZIUBAN, C.; GRAHAM, C. R.; MOSKAL, P. D.; NORBERG, A.; SICILIA, N. Blended learning: the new normal and emerging technologies. International Journal of Educational Technology in Higher Education, v. 15, n. 3, p. 1-16, 2018.

FREIRE, P. Pedagogia da autonomia. São Paulo: Paz e Terra, 1998.

GALLAGHER, S. Learning for the future of work. Swinburne University of Technology Website. 2019. Disponível em: https://www.swinburne.edu.au/new-workforce/. Acesso em 11 out. 2019.

KERSCH, D. F.; MARQUES, R. G. Redes sociais digitais na escola: possibilidades de conexão, produção de sentido e aprendizagem. Diálogo das Letras, Pau dos Ferros, v. 6, n. 2, p. 343-362, jul./dez. 2017.

MORAIS, C. T. Q. de; LIMA, J. V. de; FRANCO, S. R. K. Conceitos sobre Internet e Web. Porto Alegre: Editora da UFRGS, 2012. 
MORAIS, N. S.; CABRITA, I. Ambientes virtuais de aprendizagem: comunicação (as)síncrona e interação no ensino superior. Revista Prisma, n. 6, p. 158-179, 2008.

MORÁN, J. Mudando a educação com metodologias ativas. In: SOUZA, C. A. de; MORALES, O. E. T. (org.). Convergências Midiáticas, Educação e Cidadania: aproximações jovens. Coleções Mídias Contemporâneas - Volume II. Ponta Grossa: UEPG/PROEX, 2015a. p. 15-33.

MORALES, O. E. T. Educação híbrida: um conceito-chave para a educação, hoje. In: BACICH, L.; NETO, A. T.; TREVISANI, F de M. Ensino híbrido: personalização e tecnologia na educação. Porto Alegre: Penso, 2015b. p. 27-45.

OLIVEIRA, M. S.; TINOCO, G. A.; SANTOS, I. B. de A. Projetos de letramento e formAÇÃO de professores de língua materna. (e-book) Natal: Editora da UFRN, 2014. Disponível em: https://bit.ly/3IRWo0R. Acesso em: 11 out. 2019.

PIMENTEL, N. dos S.; TEIXEIRA, M. B. dos R. Atividades didáticas usuais adaptadas à proposta de metodologias ativas de aprendizagem. In: NEVES, V. J. das; MERCANTI, L. B.; LIMA, M. T. (org.). Metodologias Ativas: perspectivas teóricas e práticas no ensino superior. Campinas: Editora Pontes, 2018. p. 135-156.

PAIVA, V. L. M. O. A formação do professor para uso da tecnologia. In: SILVA, K. A.; DANIEL, F. G.; KANEKO-MARQUES, S. M.; SALOMÃO, A. C. B. (org.). A formação de professores de línguas: novos olhares. v. 2. Campinas: Pontes, 2013. p. 209-230.

PUNCREOBUTR, V. Education 4.0: New Challenge of Learning. St. Theresa Journal of Humanities and Social Sciences, v. 2, n. 2, p. 92-97, jul./dez. 2016.

SALMON, G. May the Fourth Be with You: Creating Education 4.0. Journal of Learning for Development, v. 6, n. 1, p. 95-115, 2019.

SPERHACKE, S. L.; HOPPE, L.; MEIRELLES, M. Metodologias ativas: ludificação de conteúdo e uso de jogos em sala de aula. Porto Alegre: CirKula, 2016.

VALENTE, J. Blended learning e as mudanças no ensino superior: a proposta da sala de aula invertida. Educar em Revista, Curitiba, Edição Especial n. 4, p. 79-97, 2014. 
- Rumo a um ensino superior 4.0: uma experiência com fórum on-line síncrono para ensino de língua inglesa na perspectiva das metodologias ativas

WALLNER, T.; WAGNER, G. Academic Education 4.0. International Conference on Education and New Developments, p. 155-159, jun. 2016.

WELP, A. K. de S.; VIAL, A. P. S. Currículo com base em projetos pedagógicos: relato de uma experiência na educação superior. Revista Entrelinhas, v. 10, n. 2, p. 230-254, jul./ dez. 2016.

COMO CITAR ESTE ARTIGO: NUNES, Mariana Backes; BARCELLOS, Patrícia da Silva Campelo Costa. Rumo a um ensino superior 4.0: uma experiência com fórum on-line síncrono para ensino de língua inglesa na perspectiva das metodologias ativas. Revista do GEL, v. 17, n. 3, p. 216-233, 2020. Disponível em: https://revistadogel.gel.org.br/

DOI: http://dx.doi.org/10.21165/gel.v17i3.2760

Submetido em: 13/10/2019| Aceito em: 02/09/2020. 